\title{
OPERATIONAL ENERGY/CARBON DIOXIDE EMISSIONS ANALYSIS COMBING BUILDING CLUSTER AND TRANSPORT DEMAND OF BUILDINGS' USERS AT THE STREET LEVEL: A CASE STUDY OF HANKOU RAILWAY STATION SURROUNDINGS IN CHINA
}

\author{
QUNFENG JI \& PHIL JONES \\ Welsh School of Architecture, Cardiff University, UK
}

\begin{abstract}
Rapidly growing energy consumption and associated carbon emissions from building clusters and transport activities have raised concerns. Predicting carbon emissions combing building clusters and transport activities due to buildings' users is an effective way to getting a better understanding of their energy use and carbon emissions, and thus to control carbon emissions for low carbon development. The purpose of this paper is to quantify and compare operational energy consumption and associated carbon dioxide emissions from building cluster and transport activities due to the buildings' occupants. The energy consumption and carbon emission features on building cluster and transport activities are then presented and analysed. Finally, relevant low-carbon development strategies in the built environment from building cluster and transport activities are outlined and discussed. The results of the case study have shown that: (1) Energy consumption and carbon emissions from building clusters are almost four times higher than transport carbon emissions due to buildings' users in the unit of the square metre per year. Therefore, more focus on energy-saving should be emphasised on the buildings sector compared to the transport sector. (2) Different building types significantly varied in energy demands. Specifically, residential buildings have the highest heating demands, while public buildings in term of commercial, office and hotel buildings consumed more energy on cooling demands. (3) Transport-related carbon emissions due to mobility from buildings' users by car and taxi are the primary sources of carbon emissions. The highest average carbon emissions come from private cars/ taxis. By contrast, public transport has the lowest average transport carbon emissions due to their per capita low carbon emission factor. Transit modes are the preferred low carbon travel modes, so these should be promoted.
\end{abstract}

Keywords: building cluster, transport activities, energy consumption, carbon emissions, street-level.

\section{INTRODUCTION}

Cities account for an estimated $75 \%$ of the world's energy, and $80 \%$ of its greenhouse gas emissions [1]. Furthermore, the construction and transport sectors are responsible for $62 \%$ of global final energy consumption [2] and 55\% of total greenhouse gas emissions [3]. This is a particular concern for China due to the country's exceptionally rapid pace of urbanisation [4]. By the end of 2011, China's urbanisation rate had reached $51.3 \%$ of the population [5]. More urban infrastructure and services will be needed to satisfy the demands of future city residents, resulting in higher energy consumption and carbon emissions from buildings and transport [6].

However, it is unclear whether carbon emissions from building clusters outweigh the transport due to the mobility of the buildings' occupants. The primary aim of this paper is to quantify and compare operational energy consumption and associated carbon dioxide emissions from building clusters and transport activities due to the buildings' occupants. The 
focus is to take into account four building types and the travel demands of their occupants from these buildings. This work presents the major findings in this research, and it finally offers insights into low-carbon development strategies in combing building cluster and transport activities at the street level.

\section{ENERGY CONSUMPTION/ CARBON EMISSIONS QUANTIFICATION}

An extensive amount of research concerns itself with energy use and carbon emissions in the built environment, and it spans numerous disciplines such as architecture, city planning, and transport planning [7], [8]. However, the themes of energy use and carbon emissions quantification from the building stocks and transport sector have always addressed separately in the previous study. For the former study, modelling energy demands and related carbon emissions from buildings is particularly useful in assessing the sustainability on buildings. These can involve either top-down or bottom-up modelling approaches, which have been studied and reviewed by many scholars [9]-[14]. For the latter theme, there are two main ways to calculate the transport carbon emissions from travel activities. Firstly, the average total fuel consumption can be calculated based on the annual mileage of transport modes, and the average consumption of fuel per kilometre of various transport modes. Then by multiplying the carbon emission coefficient in the IPCC (Intergovernmental Panel on Climate Change) guideline by the total fuel used from which the total carbon emissions from travel activities can be computed [15]. Another method is to use the model to understand the carbon emissions of various transport modes, and then multiplying it by the mileage of different transport means, the carbon emissions from all the travel activities can be calculated (ibid).

\section{RESEARCH METHOD}

The method used in this study, to quantify carbon emissions on building clusters, is based on the building cluster energy demand modelling, which is classified by four building types, and validated by the on-site survey. The technical tools are adopted by the integration of the VIRVIL plug-in and Sketchup. Modelling was done in Sketchup, and then calculations were performed in VIRVIL [16]. For carbon emissions from transport due to the buildings' users, the improved calculation method was adopted based on the annual mileage of various transport modes and non-fixed emission factors. The reason is that, on the one hand, the value of the fuel consumption of different transport modes is difficult to obtain, while their annual mileages can be found through data available through large-sample surveys from relevant research institutes; therefore, this method overcomes the difficulty resulted from the lack of data, making it more possible to calculate the carbon emissions. On the other hand, given the fact that over the past dozens of years, China's vehicle technology and fuel quality have been improved, the carbon emission factor for transport modes cannot be maintained at the same level. Based on the research of scholars [17], this research assumes that the carbon emission coefficient decreases by $0.5 \%$ annually, as this more accurately reflects reality. There were seven types of travel modes reported in this study: walk, bicycle, e-motorcycle, bus, metro, taxi and car. For the simplicity and clarity of the analysis, these modes are regrouped into three modal categories based on carbon emissions characteristics: non-motorised modes (NMM), including walking and cycling, transit modes, covering, e-motorcycles, public buses and the metro and driving modes, which includes the cars and taxis. As there are no carbon emissions from NMM, this study only considers the modes of transit and driving when predicting the carbon emissions from the transport. The following figure briefly illustrates the research method in this study. 


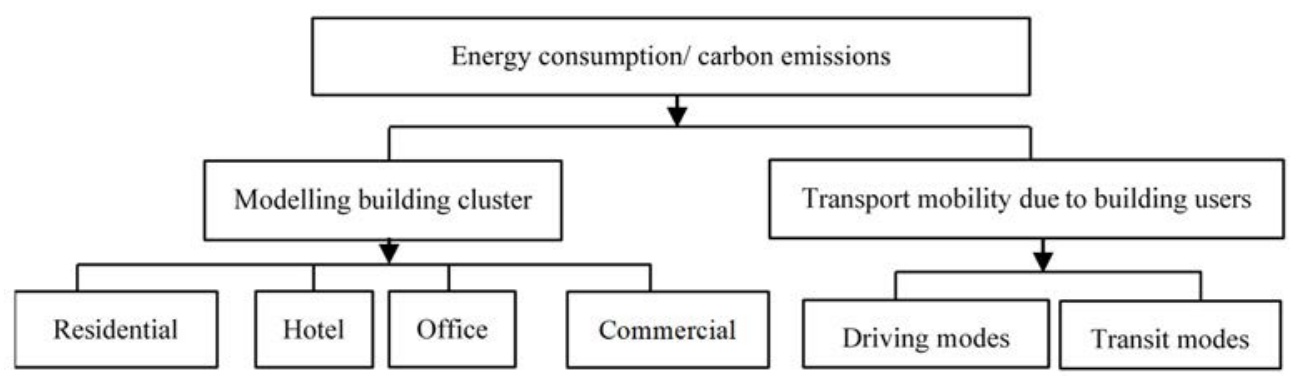

Figure 1: Research Method.

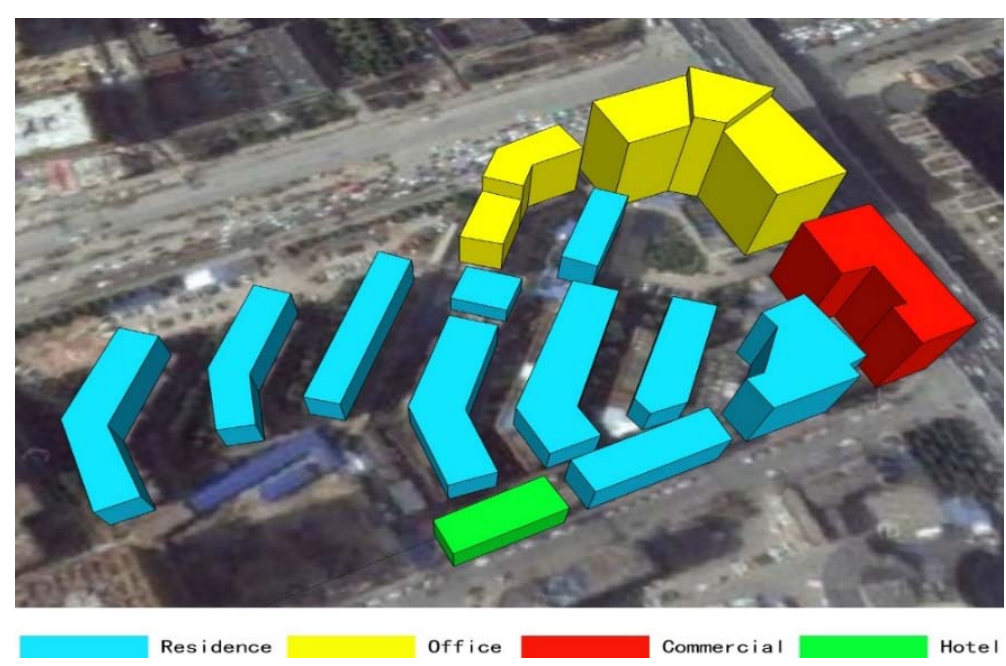

Figure 2: Modelling four building types in the study area.

\section{CASE STUDY}

\subsection{Basic description of the study area}

The study area is in the south-west of the Hankou Station, within around one kilometre of the Station. There are four types of buildings, namely residential, commercial, office, and hotel buildings. Residential buildings mainly consist of the Donghang Residential Community and the Hejiadun Community. Public buildings in Hejiadun community include the Wuhan Bureau of Education Buildings, the Wuhan Building of Science, and the Jiangfeng Building. Fig. 2 shows the 3D model in this research.

\subsection{Data collection}

According to our investigation, there were around 530 households with around 1800 people in the study area for residential use. Three public buildings, with around 2000 people. Therefore, the total number of people is around 3800. This investigation also found that most 
of the buildings in this study area are for residential use, representing $47 \%$, followed by office use $(36 \%)$, and commercial use (14\%). The following figure illustrates these data.

For the data collection in the transport activities due to the buildings' users, the survey was conducted using interviews and the questionnaires. In May 2016, six taught postgraduate students formed 2- or 3-person teams and were evenly distributed among the study areas. They investigated the study area by interviewing people mainly in locations such as entrances, major street intersections, and open spaces like the squares. Some people refused to participate in this survey because they were in a rush to get to work, or due to their own personal reasons, perhaps their own security. Four main types of travel variables - trip frequencies, trip distance, mode choices, and vehicle kilometres travelled (VKT) - are identified with travel demand, and thus transport energy consumption [18]. This study focuses on four aspects of travel: travel purpose, one-way travel time, travel distance, and travel mode, and data were collected for these aspects.

For the questionnaire of data records, some were incomplete in reporting trip activities. Some interviewees were unwilling to provide their travel information due to the privacy. Some also reported unreasonable trip times, for example, having a one-way trip distance of more than $200 \mathrm{~km}$ on a typical day. After these invalid or incomplete records had been deleted, the final sample included a total of 72 from residential buildings, and 61 from public buildings, around the Hankou Railway Stations.

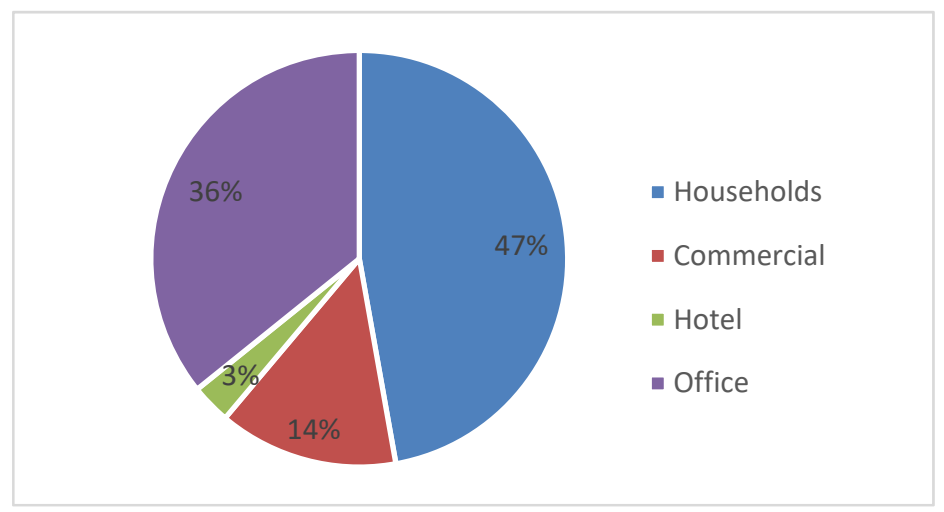

Figure 3: The proportion of the building classification from the on-site investigation.

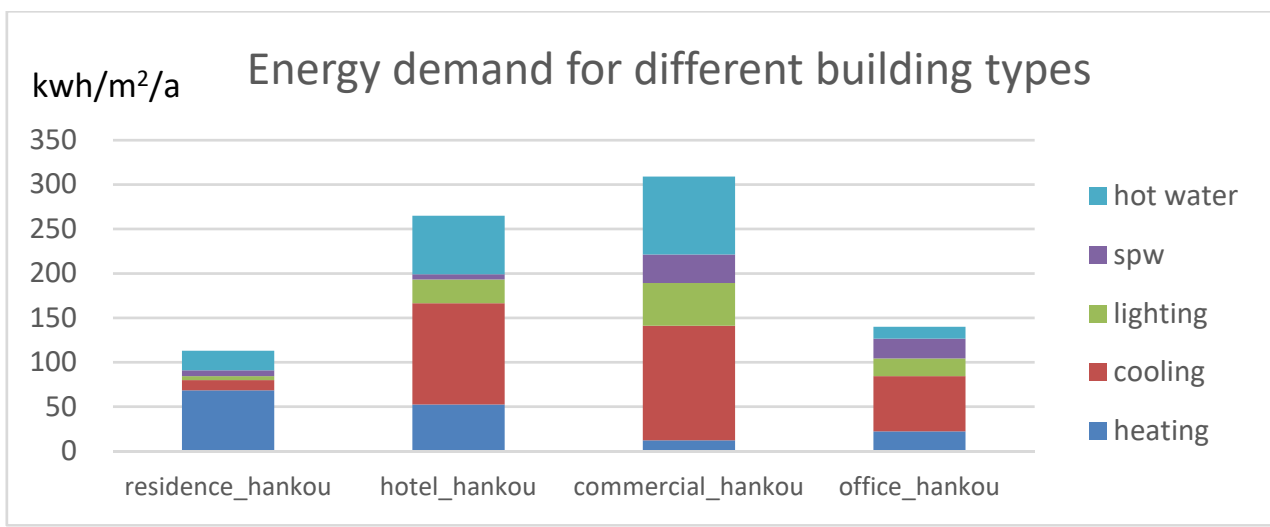

Figure 4: Energy demand from four different building types from the simulation. 


\subsection{Results calculation and analysis}

\subsubsection{Carbon emissions of the building cluster}

Fig. 4 shows that different building types have different power consumption for each component. More specifically, for residential buildings, heating, and hot water are the primary energy demands, while cooling and hot water are the main energy demands for commercial buildings, which was also observed for the hotel buildings. For office buildings, cooling was still the main demand, as well as heating, small power, and lighting. In addition, another obvious characteristic is that out of these four building categories, only residential buildings have more heating demands than cooling demands.

Furthermore, the electricity consumption from fourteen buildings around Hankou Railway Station was investigated from the Power Supply Company in two different places. One area for providing electricity consumption for the public buildings is on Xinhua Road, and the location of the source for electricity provision for residential buildings is on Changqing Road. The electricity consumption was investigated and recorded from January 2015 to April 2016. The following table presents the results for electricity consumption as well as the gas demand.

As can be seen clearly in the Fig. 5, the simulation result is larger than the measurement, but generally it meets the criterion and is within the accepted range. The error can be explained by the unstable factors in the simulation, such as the occupants' activities and longer operating schedule in the simulation than in real conditions.

There is a broad range of benchmarks for building operating energy consumption, depending on what is included, such as heating, cooling, ventilation, lighting, hot water, and small power. Some benchmarks include all of the above aspects, and some only partially cover them. The energy demand relates to the thermal loss associated with heating, cooling, and the power consumption. The energy supply refers to the delivered energy and supplied energy to the buildings. The difference between energy demand and energy supply relates to the system efficiency, in terms of the EER (energy efficiency ratio), COP (coefficient of performance), and internal loss ratio through transport and distribution, for example. Those factors are closely related to heating, cooling, and ventilation. The energy supply is sometimes described in the primary energy terms, including the gas, oil, coal, and fuels associated with electricity generation in the power stations. The carbon emissions are associated with the primary energy use. Fig. 6 describes the relationship between energy demand and energy supply.

Table 1: The investigated energy demand in the study area.

\begin{tabular}{|c|c|c|c|c|c|c|}
\hline $\begin{array}{c}\text { Building } \\
\text { types }\end{array}$ & $\begin{array}{c}\text { Floor } \\
\text { areas }\end{array}$ & $\begin{array}{c}\text { Net area used } \\
\text { by electricity }\end{array}$ & $\begin{array}{c}\text { Electricity } \\
\text { demand } \\
(\mathrm{kWh} / \text { annual })\end{array}$ & $\begin{array}{c}\text { Electricity } \\
\text { demand }(\mathrm{kWh} \\
\left./ \mathrm{annual} / \mathrm{m}^{2}\right)\end{array}$ & $\begin{array}{c}\text { Gas demand } \\
(\mathrm{kWh} / \text { annual } \\
\left./ \mathrm{m}^{2}\right)\end{array}$ & $\begin{array}{c}\text { Total } \\
(\mathrm{kWh} / \text { annual } \\
\left./ \mathrm{m}^{2}\right)\end{array}$ \\
\hline $\begin{array}{c}\text { Residential } \\
\text { buildings }\end{array}$ & 75,073 & $\begin{array}{c}30,030(40 \% \\
\text { floor area })\end{array}$ & $2,088,788$ & 70 & 9 & 79 \\
\hline Commercial & 22,187 & $\begin{array}{c}19,968(90 \% \\
\text { floor area })\end{array}$ & $4,411,800$ & 221 & 76 & 297 \\
\hline Office & 56,938 & $\begin{array}{c}34,165(60 \% \\
\text { floor area })\end{array}$ & $2,747,657$ & 80 & 6 & 86 \\
\hline Hotel & 4,881 & $\begin{array}{c}3,905(80 \% \\
\text { floor area })\end{array}$ & 905,960 & 232 & 0 & 232 \\
\hline
\end{tabular}




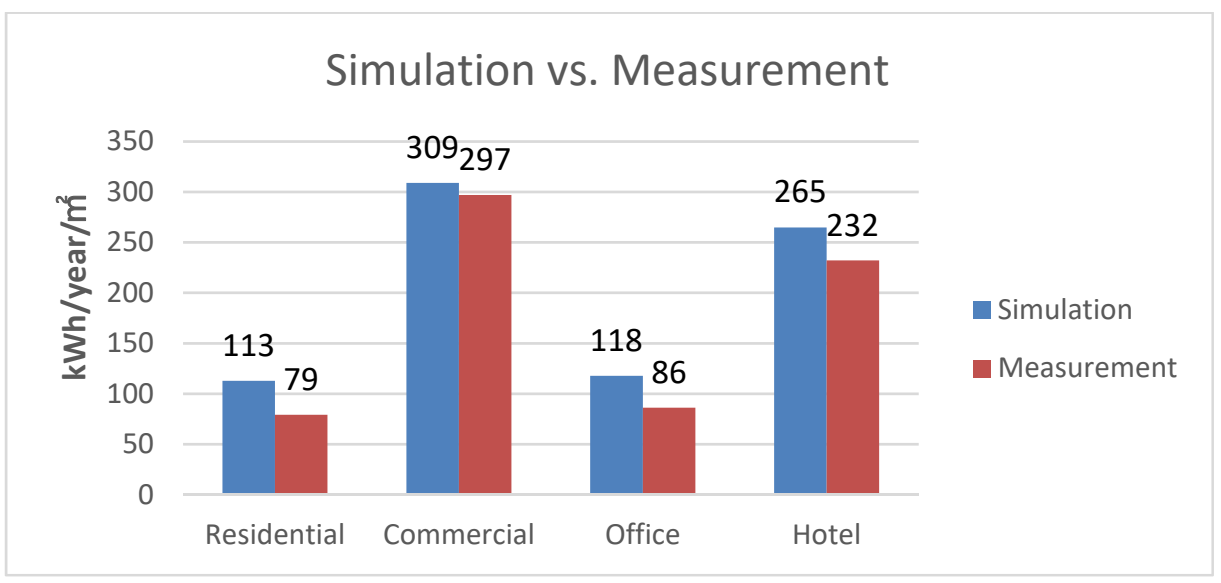

Figure 5: The energy demand of simulation vs. measurement.

\section{Operating Energy}

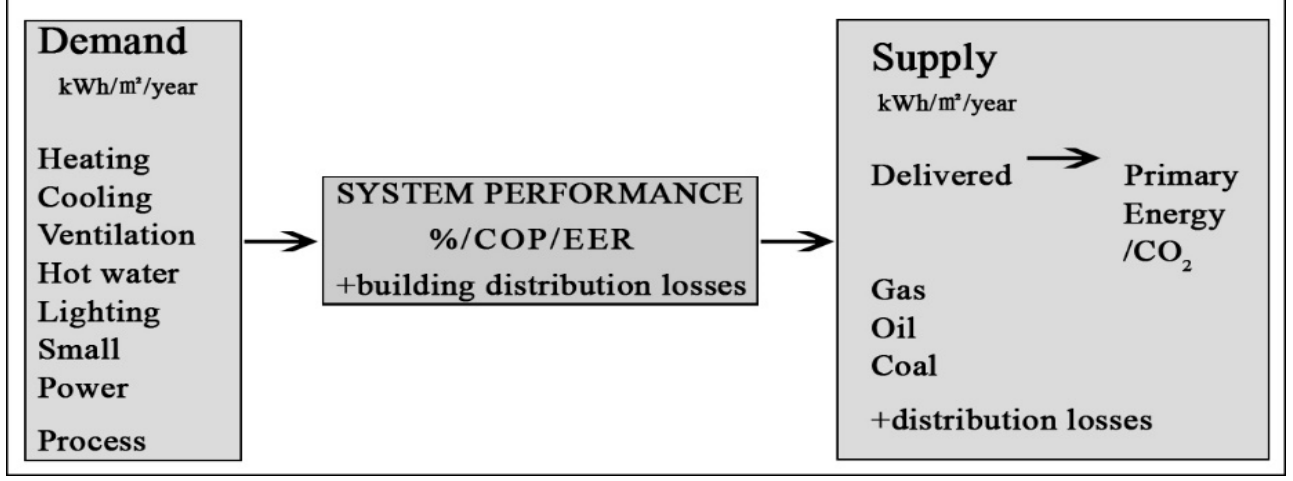

Figure 6: The relationship between energy demand and supply [21].

Fig. 7 presents the annual electricity supply per square metre. It is noticeable that commercial and hotel buildings have the highest electricity consumption, standing at 188 $\mathrm{kWh} /$ annual $/ \mathrm{m}^{2}$ and $184 \mathrm{kWh} /$ annual $/ \mathrm{m}^{2}$ respectively. These figures are markedly high than the electricity consumption for office and residential buildings $\left(88 \mathrm{kWh} / \mathrm{annual} / \mathrm{m}^{2} \mathrm{vs.} 62\right.$ $\mathrm{kWh} / \mathrm{annual} / \mathrm{m}^{2}$ ).

Fig. 8 presents the gas supply for four different building types. Commercial buildings are shown to the largest gas supply, with about $62 \mathrm{kWh} / \mathrm{annual} / \mathrm{m}^{2}$ in hot water compared to around $8 \mathrm{kWh} /$ annual $/ \mathrm{m}^{2}$ for residential building, and $6 \mathrm{kWh} /$ annual $/ \mathrm{m}^{2}$ for office buildings. Hotel buildings do not use gas to heat water. At the same time, none of the four building types uses gas for heating.

Finally, Table 2 illustrates the carbon emissions from building cluster. The total annual carbon emissions generated by electricity and gas are $70 \mathrm{~kg} \mathrm{CO}_{2} / \mathrm{m}^{2} /$ annual and $11400 \mathrm{t} \mathrm{CO}_{2} /$ annually. Moreover, carbon emissions from electricity consumptiom are largely higher than those caused by gas consumption. 


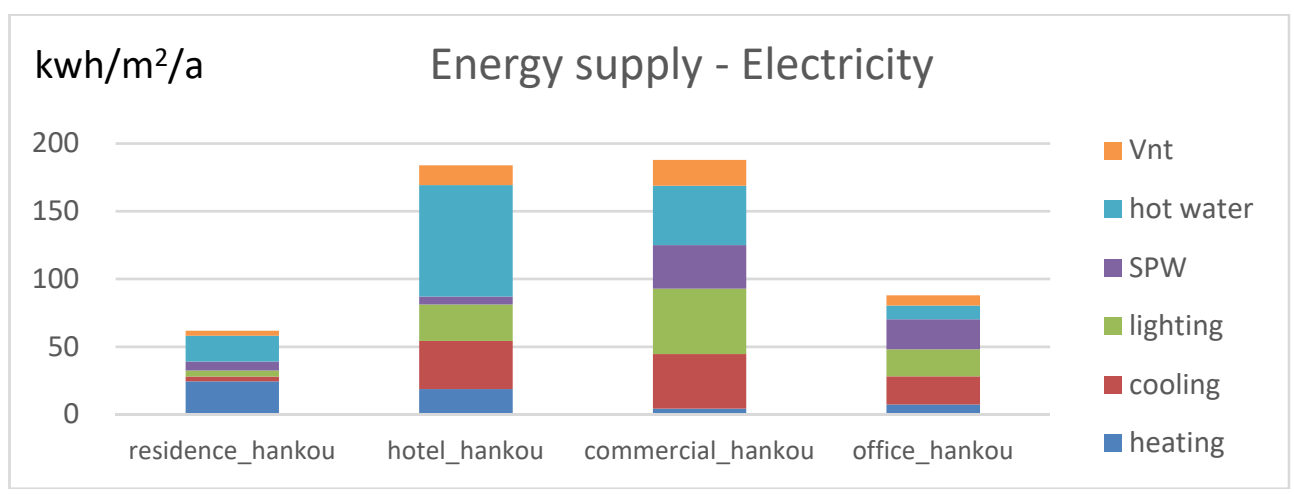

Figure 7: Energy supply by electricity from the simulation.

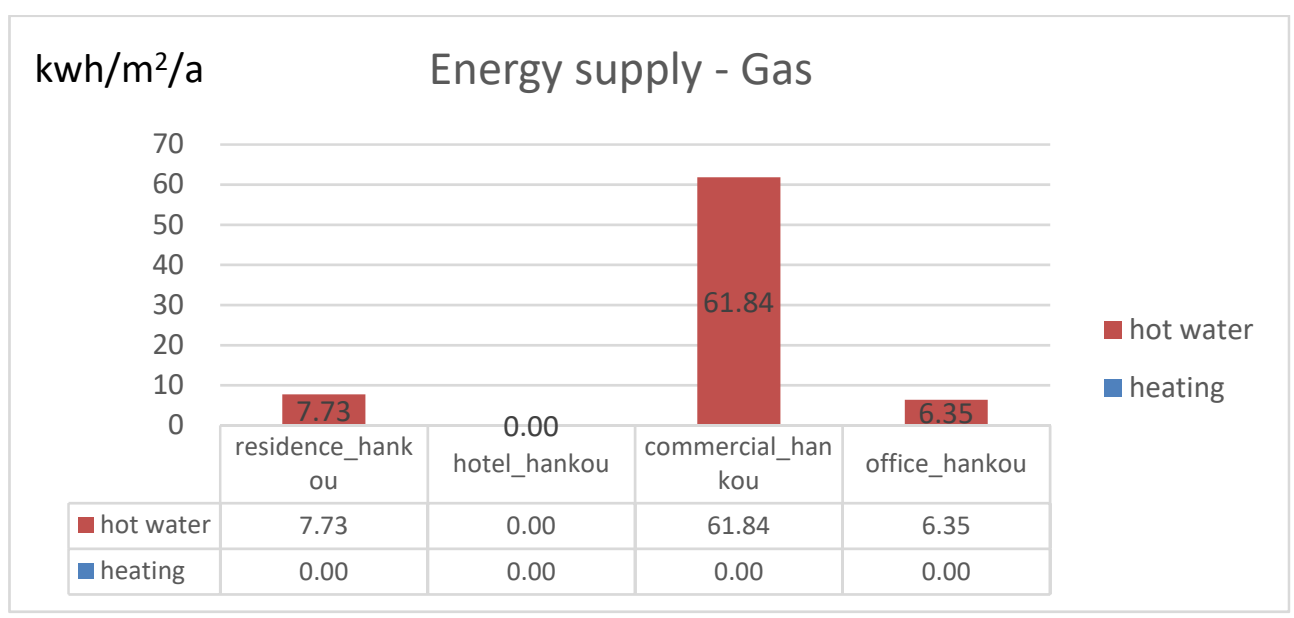

Figure 8: Energy supply by gas from the simulation.

Table 2: Annually operational carbon emissions from buildings.

\begin{tabular}{|c|c|c|c|c|}
\hline \multicolumn{2}{|c|}{ Operating carbon } & Electricity & Gas & Total \\
\hline \multicolumn{2}{|c|}{ Internal loss ratio (through transport and distribution) } & 0.07 & 0.07 & \\
\hline Carbon dioxide emission factor & $\mathrm{tCO}_{2} / \mathrm{MWh}$ & 0.97 & 0.20 & \\
\hline \multirow{2}{*}{ Carbon dioxide emission } & $\mathrm{kgCO}_{2} / \mathrm{m}^{2} /$ annual & 67 & 3 & 70 \\
\cline { 2 - 5 } & $\mathrm{tCO}_{2} /$ annual & 10909 & 521 & 11431 \\
\hline
\end{tabular}

Note: carbon emission factors (0.97) is based on the reference: China's regional power grid baseline emission factor in 2014.

4.3.2 Carbon emissions from transport activities due to buildings' users

Information about the respondents' travelling distance by different modes was used to calculate their transport energy use during the investigated periods. Carbon emissions from transport due to the travel activities from buildings can be estimated according to the following eqn (1) [19]: 


$$
\mathrm{C}=\sum_{i} V K T_{i} * E F_{i}
$$

Where $C$ represents the carbon emissions in the unit of $\mathrm{kg}$; VKT stands for the annual distance travelled, measured in the unit of $\mathrm{km}$ (i.e. Vehicles Kilometres Travelled), EF symbolises the carbon emission factors of various transport modes in the unit of $\mathrm{kg} / \mathrm{km}$, and i signifies different transport modes.

Regarding carbon emission factors from public buses, the metro, taxis, and cars in Wuhan, we use the emission factors from Beijing and Shanghai as the basic reference to calculate carbon emission factors of different transport modes in Wuhan due to the lack of emission data in Wuhan. As mentioned before, considering the rapid evolution of the technology in the transport system, carbon emission factors need regular adjustment, i.e. every 3 to 5 years. As a result, this research adopts the improved method of the carbon emission factors by assuming that the carbon emission coefficient decreased by $0.5 \%$ annually based within the city of Beijing and Shanghai in the year 2006, for this is more in-line with the reality. The updated carbon emission factors are presented in the Table 3.

According to the survey data of different transport modes measured in the distance travelled from the sample, we can calculate the transport carbon emissions due to the occupants of residential buildings, and public buildings, respectively. The final results are present in Tables 4 to 7 .

Table 3: The updated emission factors adopted in this research [17], [20].

\begin{tabular}{|l|l|l|l|l|l|}
\hline Transportation modes & Public bus & Metro & Taxi & Cars & E-motor \\
\hline $\mathrm{CO}_{2}$ emission $\left./ \mathrm{km}\right)$ & 1.013 & 2.059 & 0.224 & 0.204 & 0.019 \\
\hline
\end{tabular}

Table 4: $\quad$ Per capita value of different transport modes carbon emissions from residential buildings.

\begin{tabular}{|c|c|c|}
\hline $\begin{array}{c}\text { Transportation } \\
\text { modes }\end{array}$ & $\begin{array}{c}\text { Daily transport carbon emissions } \\
(\mathrm{kg} / \text { person/day) }\end{array}$ & $\begin{array}{c}\text { Annual transport carbon } \\
\text { emissions }\end{array}$ \\
\hline Public bus & 0.20 & 73.82 \\
\hline Metro & 0.014 & 4.98 \\
\hline Taxi & 6.42 & 2343.79 \\
\hline Private cars & 6.05 & 2206.72 \\
\hline E-motor & 0.43 & 156.66 \\
\hline
\end{tabular}

Note: we regard the passenger capacity for the public buses as 80 persons; metro passenger capacity as 285 per compartment, and usually the Wuhan Metro has eight compartments. As a result, the passenger capacity for metro is $285 * 8=2280$ persons.

Table 5: Total carbon emissions due to travel activities from residential buildings.

\begin{tabular}{|c|c|}
\hline Total carbon emissions (kg/annual) & 704,089 \\
\hline Annual per capita carbon emissions ( kg/person/annual $)$ & 579 \\
\hline Annual per capita carbon emissions $\left(\mathrm{kg} / \mathrm{m}^{2} /\right.$ annual $)$ & 9.4 \\
\hline
\end{tabular}


Table 6: Per capita value of different transport modes carbon emissions from public buildings.

\begin{tabular}{|c|c|c|}
\hline $\begin{array}{c}\text { Transportation } \\
\text { modes }\end{array}$ & $\begin{array}{c}\text { Daily transport carbon emissions } \\
(\mathrm{kg} / \mathrm{person} / \text { day })\end{array}$ & $\begin{array}{c}\text { Annual transport carbon } \\
\text { emissions }\end{array}$ \\
\hline Public bus & 0.30 & 109.32 \\
\hline Metro & 0.026 & 9.44 \\
\hline Taxi & 3.43 & 1250.92 \\
\hline Private cars & 5.04 & 1840.18 \\
\hline E-motor & 0.19 & 69.35 \\
\hline
\end{tabular}

Table 7: Total carbon emissions due to travel activities from public buildings.

\begin{tabular}{|c|c|}
\hline Total carbon emissions (kg/annual) & 682,499 \\
\hline Annual per capita carbon emissions (kg/person/annual) & 431.53 \\
\hline Annual per capita carbon emissions ( $\mathrm{kg} / \mathrm{m}^{2} /$ annual $)$ & 8.4 \\
\hline
\end{tabular}

Table 8: Carbon emissions comparison between building cluster and transport sector.

\begin{tabular}{|c|c|c|}
\hline & Building sector & Transport sector \\
\hline Total carbon emissions ( $\mathrm{t} \mathrm{CO}_{2} /$ annual $)$ & 11431 & 1386 \\
\hline $\begin{array}{c}\text { Annual per capita carbon emissions } \\
\left(\mathrm{kg} / \mathrm{m}^{2} / \text { annual }\right)\end{array}$ & 70 & 18 \\
\hline
\end{tabular}

\subsection{Strategies to control carbon emissions}

According to the above results and analysis, strategies are mainly outlined for building clusters and their transport activities for the buildings' users. Firstly, energy-saving should be more of a focus on building clusters compared to transport carbon emissions. More specifically, energy-saving in residential buildings should be controlled in terms of heating demands, but in terms of the cooling demands for public buildings. Secondly, from the results of the transport carbon emissions, transit and public oriented modes should be promoted, and this can reduce transport carbon emissions due to the lowest capita carbon emission factor and the lowest possibility of using the private travelling modes. Lastly, to reduce transport carbon emissions, the main core idea seeks to avoid unnecessary travel and reduce trip distances by private vehicles. Approaches such as public transport and non-motorised modes must be promoted, and transport demand management in the shape of fuel policies, road charging, and parking pricing, for example. Finally, the integration of actions and measures for transport planning, land use, and mixed land use development can effectively increase accessibility and reduce trip distance.

\subsection{Conclusions}

Buildings and transport sectors are the dominant sources of energy consumption and carbon emissions from the built environment. Significant research has been conducted to investigate 
energy use and associated carbon emissions. The main research areas are the building clusters' operational energy consumption and carbon emissions, and the transport emissions due to the mobility of the buildings' users. This paper focuses on the street scale, and relevant conclusions are presented according to this study as follows:

(1) Annual energy consumption and carbon emissions from building clusters are higher than transport carbon emissions, and the figure is almost four times greater (Table 8 shows). Consequently, this should be a greater focus on energy-saving in the building sector. More specifically, heating demands should be controlled in residential buildings, while cooling demands must be controlled in public buildings.

(2) Different building types significantly varied in terms of energy demand. Residential buildings have the highest energy consumption in heating demands, while public buildings in term of commercial, office, and hotel buildings consume more energy through cooling demands.

(3) Transport carbon emissions due to buildings' user mobility from cars and taxis are the primary sources of transport carbon emissions. The highest carbon emissions come from private cars, followed by taxis. Transit modes such as the underground are the preferable low carbon travel modes, and should therefore be promoted.

\section{REFERENCES}

[1] Williams, B., Statement on Climate Change at the UN Commission on Sustainable Development $15^{\text {th }}$ Session, New York, 2007.

[2] IEA, World Energy Outlook, 2011.

[3] Anderson, J.E. et al., Energy analysis of the built environment - A review and outlook. Renewable and Sustainable Energy Reviews, 44, pp. 149-158, 2015.

[4] National Bureau of Statistics of China. China statistical yearbook, Beijing: China Statistics Press, 2014.

[5] Khanna, N., Evaluating China's pilot low carbon city initiative: national goals and local plans. The European Council for an Energy-Efficient Economy 2013 Summer Study on Energy Efficiency, Toulon, France, Jun. 3-8, 2013, Online. Available at: http://escholarship.org/uc/item/9t51z8ds.pdf. Accessed on: 5 Oct. 2015.

[6] Zhou, N., China's development of low-carbon eco-cities and associated indicator systems, Online. Available at: http://escholarship.org/uc/item/0f4967nd.pdf. Accessed on: 17 Feb. 2015.

[7] Jones, C. \& Kammen, D.M., Spatial distribution of US household carbon footprints reveals suburbanization undermines greenhouse gas benefits of urban population density. Environmental science \& technology, 48(2), pp. 895-902, 2014.

[8] Ewing, R. \& Cervero, R., Travel and the built environment. Journal of the American Planning Association, 76(3), pp. 265-294, 2010.

[9] Swan, L.G. \& Ugursal, V.I., Modelling of end-use energy consumption in the residential sector: A review of modelling techniques. Renewable and Sustainable Energy Reviews, 13(8), pp. 1819-1835, 2009.

[10] Kavgic, M. et al., A review of bottom-up building cluster models for energy consumption in the residential sector. Building and Environment, 45(7), pp. 16831697, 2010.

[11] Foliente, G. \& Seo, S., Modelling building stock energy use and carbon emission scenarios. Smart and Sustainable Built Environment, 1(2), pp. 118-138, 2012.

[12] Heiple, S. \& Sailor, D.J., Using building energy simulation and geospatial modelling techniques to determine high-resolution building sector energy consumption profiles. Energy and Buildings, 40(8), pp. 1426-1436, 2008. 
[13] Snäkin, J.P., An engineering model for heating energy and emission assessment the case of North Karelia, Finland. Applied Energy, 67(4), pp. 353-381, 2000.

[14] Huang, Y. \& Brodrick, J., A bottom-up engineering estimate of the aggregate heating and cooling loads of the entire US building cluster. Lawrence Berkeley National Laboratory, Online. Available at: http://escholarship.org/uc/item/5hv2t661.pdf. Accessed on: 21 Oct. 2015.

[15] Huang, J., et al., The Effect of Traffic Facilities Accessibility on Household Commuting Caused Carbon Emission: A Case Study of Wuhan City, China [In Chinese]. Urban Planning International, 30, pp. 97-105, 2015.

[16] Jones, P. et al., Modelling the built environment at an urban scale-Energy and health impacts in relation to housing. Landscape and Urban Planning, 83(1), pp. 39-49, 2007.

[17] Liu, W., Influence factors and guidance strategy of low carbon travel for urban resident in China. PhD Dissertation from Beijing Institute of Technology, 2014.

[18] Ewing, R. \& Cervero, R., Travel and the built environment: a synthesis. Transport Research Record: Journal of the Transport Research Board, (1780), pp. 87-114, 2001.

[19] Cai, B. et al., Estimates of China's national and regional transport sector $\mathrm{CO}_{2}$ emissions in 2007. Energy Policy, 41, pp. 474-483, 2012.

[20] Zhao, M. et al., Resident travel modes and $\mathrm{CO}_{2}$ emissions by traffic in Shanghai city. Research of Environmental Sciences, 22(6), pp. 747-752, 2009.

[21] Jones, P. et al., 2011. LCRI-CISDI Low carbon master plan guidance. Available at: http://orca.cf.ac.uk/49347. Accessed on: 20 Jun. 2016. 